\title{
Rheocricotopus (s. str.) costai sp. n. AND R. (s. str.) pyrenaeus sp. n., TWO RELICT SPECIES FROM GLACIAL RHEOCRENES AND STREAMS IN CORSICA AND THE EASTERN PYRENEES (DIPTERA: CHIRONOMIDAE, ORTHOCLADIINAE)
}

\author{
Joel MOUBAYED-BREIL ${ }^{1 *}$, Patrick ASHE ${ }^{2}$ \\ ${ }^{1}$ Freshwater \& Marine biology, 10 rue des Fenouils, F-34070 Montpellier, FRANCE \\ 233 Shelton Drive, Terenure, Dublin 12, D12 PK68, IRELAND \\ * Corresponding author: ORCID ID: orcid.org/0000-0002-6793-5746, e-mail: jm.aquabiol@ free.fr
}

Cite this article as:

Moubayed-Breil, J. \& Ashe, P. 2019. Rheocricotopus (s. str.) costai sp. n. and R. (s. str.) pyrenaeus sp. n., two relict species from glacial rheocrenes and streams in Corsica and the eastern Pyrenees (Diptera: Chironomidae, Orthocladiinae). Trakya Univ J Nat Sci, 20(1): 35-46, DOI: 10.23902/trkjnat.493928

\begin{abstract}
Two new species of the genus Rheocricotopus subgenus Rheocricotopus (R. costai sp. n. and R. pyrenaeus $\mathrm{sp} . \mathrm{n}$.) are diagnosed and described, based on material collected in some glacial rheocrenes and streams located in the high mountains of Corsica and the Eastern Pyrenees. Rheocricotopus costai sp. n. is described as male and pupal exuviae, while R. pyrenaeus sp. $\mathrm{n}$. is described as male and female adults and pupal exuviae. Rheocricotopus costai sp. n. is known from both western Corsica and the Eastern Pyrenees, while the geographical distribution of $R$. pyrenaeus $\mathrm{sp}$. $\mathrm{n}$. is restricted to the protected area of the Mantet Nature Reserve (Eastern Pyrenees). Larvae of both $R$. costai $\mathrm{sp} . \mathrm{n}$. and $R$. pyrenaeus sp. n. are exclusively rheophilic being confined to lotic habitats located at high altitude (crenal and rhithral). Apart from the presence of an additional median circular small patch of spinules on tergite III of the exuviae, R. costai sp. n. directly keys into the effusus-group on the basis of several specific characters found in the male adult. Nevertheless, $R$. pyrenaeus sp. n. keys near both of $R$. reduncus Sæther \& Schnell, 1988 (known from Finland, Norway and Russian Far East) and R. tchernovskii Makarchenko \& Makarchenko, 2005 (known from Russian Far East), based in particular, on the unusual shape of the superior volsella which is inwardly markedly turned over distally. The genus Rheocricotopus is currently represented by 10 species in continental France and by 8 species in Corsica (Moubayed-Breil 2016). Consequently, the description of $R$. costai sp. $\mathrm{n}$. and R. pyrenaeus sp. $\mathrm{n}$. increases the total number in the genus to 12 for continental France and to 9 for Corsica. Taxonomic remarks, discussion and comments on the ecology and geographical distribution of the two new species are given.
\end{abstract}

Key words: Rheocricotopus (s. str.), new species, Diptera Chironomidae, glacial rheocrenes, Corsica, continental France, conservation.

\begin{abstract}
Özet: Bu çalışmada, Korsika ve Pireneler'deki yüksek dağlarda yer alan glasiyal rheokrenler ve akarsulardan toplanmış materyal incelenmiş ve Rheocricotopus cinsine ait iki yeni tür (R. costai $\mathrm{sp}$. n. and $R$. pyrenaeus $\mathrm{sp}$. n.) tanımlanmıştır. Rheocricotopus costai sp. n. erkek birey ve pupal kılıf ile tanımlanırken $R$. pyrenaeus sp. n. yetişkin erkek ve dişi bireyler ve pupal kılıf ile tanımlanmıştır. Rheocricotopus costai sp. n. hem Batı Korsika'dan hem de Pireneler'in doğusundan elde edilirken $R$. pyrenaeus sp. n.'nın coğrafik dağılımı Doğu Pirenler'de bir koruma alanı olan Mantet doğa koruma alanı ile sınırlıdır. Hem $R$. costai sp. n. hem de $R$. pyrenaeus sp. n. larvaları yüksek rakımlardaki lotik habitatlarda sinırlı olduklarından reofilik özelliktedirler. Rheocricotopus costai sp. n., pupal kılıfin 3. tergiti üzerinde medyan alanda yer alan küçük dairesel spinül yamasına ek olarak yetişkin erkeklerdeki çeşitli spesifik karakterleri ile effusus-grubu içinde yer almaktadır. Rheocricotopus pyrenaeus sp. n. ise özellikle distalde içe doğru dönük olan superior volsellanın olağan olmayan şekli bakımından Finlandiya, Norveç ve Uzak Doğu Rusyası'ndan bilinen $R$. reduncus Sæther \& Schnell, 1988 ile Uzak Doğu Rusyası'ndan bilinen $R$. tchernovskii Makarchenko \& Makarchenko, 2005'e benzemektedir. Rheocricotopus cinsi Fransa'da 10, Korsika'da ise 8 tür ile temsil edilmekteydi (Moubayed-Breil 2016). Sonuç olarak, $R$. costai sp. n. and R. pyrenaeus sp. n.'nın tanımlanması ile cinsin Fransa'daki tür sayısı 12'ye, Korsika'daki tür sayısı ile 9'a çıkmıştır. İki yeni türün ekolojileri ve coğrafik dağılımları ile ilgili taksonomik notlar, görüşler ve değerlendirmeler verilmiştir.
\end{abstract}

\section{Introduction}

Data on the taxonomy and geographical distribution of the known Rheocricotopus species from Europe and some neighbouring areas (Brundin 1956, Lehmann 1969, Chaudhuri \& Sinharay 1983, Sæther 1986, Sæther \& Schnell 1988, Coffman et al. 1986, Langton 1991, Wang \& Zheng 1989, Bhattacharyay et al. 1991, Wang 1995,
Wang \& Sæther 2001, Makarchenko \& Makarchenko 2005, Langton \& Pinder 2007, Ashe \& O'Connor 2012, Ree 2013, Sæther \& Spies 2013, Liu et al. 2014a, 2014b, Moubayed-Breil 2016) shows that there are currently about 77 valid species and subspecies worldwide of which only 13 are reported from Europe. Members of the genus 
Rheocricotopus Thienemann \& Harnisch, 1932 consist of exclusively rheophilic species which are encountered in lotic habitats extended from the upper reaches of streams (crenal, rhithral and peat bogs) to the lower reaches of rivers (potamal).

The genus Rheocricotopus has been revised and divided into two subgenera (Psilocricotopus and Rheocricotopus) by Sæther (1985), who recognised and created three different groups within each subgenus: godavarius-group, chalybeatus-group and atripes-group for Psilocricotopus subgenus; effusus-group, fuscipes-group and tuberculatusgroup for Rheocricotopus subgenus.

Rheoccricotopus costai sp. n. and R. pyrenaeus are diagnosed and described based on material collected in some glacial rheocrenes and streams located in the high mountains of Corsica and the Pyrenees. Rheoccricotopus costai $\mathrm{sp} . \mathrm{n}$. is described as male adult and pupal exuviae, while $R$. pyrenaeus sp. $\mathrm{n}$. is described as male and female adults and pupal exuviae.

The two new described species directly key into the effusus-group created by Sæther (1986) for known Rheocricotopus species (Nearctic, Palaearctic and Oriental Regions), on the basis of the following characters found in the male adult and pupal exuviae: humeral pit reduced or ellipsoid with smaller separate ellipsoid pit below; superior volsella rounded or right-angled with distal short or long pronounced projection; gonostylus with or without long crista dorsalis; frontal setae present on frontal apotome; median circular patch of spines/or strong spinules present on tergites IV-VI. Meanwhile the male adult and pupal exuviae of $R$. costai sp. n. show some morphological affinities with some members of the effusus-group, those of $R$. pyrenaeus $\mathrm{sp}$. n. keys near both $R$. reduncus Sæther \& Schnell, 1988 and $R$. tchernovskii Makarchenko \& Makarchenko, 2005 on the basis, in particular, of the unusual shape of the superior volsella which is markedly turned over inwards distally. Moreover, $R$. costai sp. n. seems to belong to a local 'Pyreneo-corsican element', based on the presence of an additional small median patch of spinules on tergite III of the exuviae. Consequently, a fourth additional group within the subgenus Rheocricotopus, the 'reduncusgroup', could be created which would include, $R$. reduncus, $R$. tchernovskii and $R$. pyrenaeus sp. $\mathrm{n}$.

According to Moubayed-Breil (2016), there are 13 valid Rheocricotopus species known from Europe, of which 10 are reported from France: $R$. atripes (Kieffer, 1913); R. chalybeatus (Edwards, 1929); R. gallicus Lehmann, 1969; R. glabricollis (Meigen, 1830); $R$. meridionalis Moubayed-Breil, 2016; R. subacutus Caspers \& Reiss, 1989; R. thomasi Moubayed-Breil, 2016; R. tirolus Lehmann, 1969; R. effusus (Walker, 1856 ) and $R$. fuscipes (Kieffer, 1909). Consequently, the description here of $R$. (R.) costai sp. n. and $R$. (R.) pyrenaeus $\mathrm{sp}$. $\mathrm{n}$. currently increases the total number of species in the genus Rheocricotopus to 12 from France and to 15 in Europe.
In this paper, $R$. costai sp. n. (known from western Corsica and France) and R. pyrenaeus sp. n. (known from south western France) are diagnosed and described based on material collected in glacial springs and streams at high altitude. Rheocricotopus costai sp. n. is identical with ' $R$. (Rh.) sp. 1' in Moubayed-Breil \& Ashe (2012), while $R$. (Rh.) pyrenaeus sp. $\mathrm{n}$. is the same as ' $R$. (Rheocricotopus) sp. 1' in Moubayed-Breil \& Ashe (2016). The first new species (R. costai ) is described as male adult and pupal exuviae, the second ( $R$. pyrenaeus ) as male and female adults and pupal exuviae.

\section{Materials and Methods}

The examined material was collected using some standard methods: Surber net for the benthos (larvae and pupae); Brundin drift nets for pharates, pupae and drifted pupal exuviae; troubleau net for individuals floating on the surface of the water and a sweep net for flying adults. Male adults were preserved in $80 \%$ Ethanol, then cleared of musculature in $90 \%$ lactic acid (head, thorax, abdomen and anal segment) for about 60 to 80 minutes, but can be left overnight at room temperature without any detrimental effect or damage. The specimens were checked under a binocular microscope after 20 minutes in lactic acid to determine how the clearing was progressing. When clearing was complete the specimens were washed in two changes of $70 \%$ Ethanol to ensure that all traces of lactic acid were removed.

The studied material was mounted in polyvinyl lactophenol. Before the final slide mountings (dorsally) of the male holotype and paratype material, the hypopygium including the IX ${ }^{\text {th }}$ tergum, the anal point, the gonocoxite and the gonostylus, were viewed ventrally and laterally to examine and draw from both sides all the necessary details of each species. In particular, the ventral view of the hypopygium was illustrated when the anal point and tergite IX were removed.

Part of the abdomen and the halters of the male adults were preserved in $85 \%$ ethanol for an eventual DNA analysis. Morphological terminology and measurements follow that of Sæther $(1980,1985)$ and Langton \& Pinder (2007) for the adults and Sæther (1980) and Langton (1991) for the pupal exuviae. Taxonomic remarks on some related species from Europe and neighbouring geographical areas, as well as discussion and comments on the ecology and geographical distribution of the two new species are provided.

\section{Descriptions}

Rheocricotopus (Rheocricotopus) costai sp. $\mathbf{n}$. LSID:urn:1sid:zoobank.org:act:D1B65F1D-6893-4B49-

\section{Material examined}

Holotype. Corsica. 1 male adult, leg. J. MoubayedBreil, glacial stream, upper basin of the Asco River at the locality of 'High-Asco', (42 $\left.{ }^{\circ} 27^{\prime} 13^{\prime \prime} \mathrm{N}, 09^{\circ} 01^{\prime} 57^{\prime} \mathrm{E}\right)$, altitude 1550-1800 m, 05.VI.2015. 
Paratype (all, leg. J. Moubayed-Breil). Corsica. 1 male pharate adult, same locality and data as for holotype. Continental France (Eastern Pyrenees, biogeographical zone $8 \mathrm{a}$, as given in Moubayed-Breil \& Ashe (2016), 1 male pharate adult and 2 female pharate adults, glacial springs and streams, upper basin of the River Tech, $\left(42.428^{\circ} \mathrm{N}, 2.361^{\circ} \mathrm{E}\right)$, alt. $1800-2000 \mathrm{~m}, 03$. VI.2005. 1 male adult, glacial springs and streams, Pic Carlit $\left(42.57^{\circ}\right.$ $\mathrm{N}, 1.93^{\circ} \mathrm{E}$ ), alt. $2000 \mathrm{~m}, 05 . \mathrm{VI} .2001$. Environmental data of aquatic habitat: crystalline water, conductivity 35-40 $\mu \mathrm{S} / \mathrm{cm}, \mathrm{pH}$ 5.5-5.7; temperature $8-12^{\circ} \mathrm{C}$.

The Holotype (male adult, on one slide) is deposited in the collections of the National Museum of Ireland, Kildare Street, Dublin 2, Ireland. Remaining paratypes are deposited in the senior author's collection.

Type material was preserved in $80 \%$ ethanol, and later mounted in polyvinyl lactophenol. For each adult, the head, thorax and abdomen were cleared in $90 \%$ lactic acid, then washed in $70 \%$ ethanol before mounting on slides.

Etymology: The new species is named "costai" in honour of Jacques Costa (president of the Nature Regional Park of Corsica), who is actively contributing to preserving the environment and species associated with all aquatic habitats occurring in the protected areas of Corsica.

\section{Diagnostic characters}

Apart from the presence of an additional median small patch of spinules on tergite III of exuviae, $R$. costai sp. n. belongs to the effusus-group based on some other characters found in the male adult: humeral pit elongate ellipse-like, superior volsella with a pronounced distal projection. However, this new species can be distinguished from other related members of the effusus-group in having:

- male adult. Coronal area with 2 coronals (1 seta on each side); lobes of antepronotum not gaping and thinner medially; tarsomere tas of PI, PII and PIII entirely blackish; sensilla chaetica present on tarsomeres ta 4 -ta 5 of PI, PII and PIII; humeral pit extremely elongate ellipsoid, narrowing distally, with a distinct smaller separate oval pit below; tergite IX with a weak hump medially, which is clearly visible in lateral view; anal point with 12-14 lateral setae, apex unusually rounded; superior volsella broadly bent downwards, nose-like apically, distal part short and distinctly projecting downwards; inferior volsella long, finger-like in shape, dorsal side large and lobe-like, ventral side triangular; posterior side of gonostylus swollen medially and abruptly narrowing apically, anterior side with 2 rows of setae at obtuse angle; crista dorsalis short, tooth-like, only visible when viewed laterally and at right-angle, located distally and occupying 20 to $30 \%$ of the total length of the gonostylus.

- pupal exuviae. Frontal apotome weakly covered with wrinkles; thoracic horn finger-like and strongly toothed on one side. Circular median patch of spines and spinules present on tergites III-VI; patch on tergite III smaller and armed with short spinules; patches on tergites IV-VI are subequal, more extensive and armed with much bigger and longer spines.

\section{Male imago}

( $\mathrm{n}=3: 1$ male adult and 2 male pharate adults; Figs. 1$5,9,12,14-16,19-21,31)$

$=$ "R. (Rh.) sp. 1" in Moubayed-Breil \& Ashe (2012)

Large sized species (among the largest species of Rheocricotopus s. str.). Total length 3.45-3.55 mm. Wing length 1.60-1.65 mm. General colouration variable from dark brown to blackish. Head, antenna and halters dark brown. Thorax dark brown with blackish mesonotal stripes; humeral pit brownish. Legs dark brown, tarsomeres ta 5 of PI, PII and PIII blackish (Fig. 5). Abdominal tergites and anal segment dark brown. Head. Eyes hairy, elongated vertically. Coronal area (Fig. 31) with 2 coronals (1 seta on each side); Temporal setae 10, including 5 inner, 3 outer verticals and 2 postorbitals. Palp 5-segmented, length $(\mu \mathrm{m})$ of palpomeres 1-5: 45, 30, 85, 95, 105; distal part of third palpomere (Fig. 1) with 3 sensilla clavata and 4 sensilla coeloconica (Fig. 2). Clypeus (Fig. 3) semicircular, bearing 12 setae in 3 rows. Antenna $970 \mu \mathrm{m}$ long, last flagellomere $520 \mu \mathrm{m}$ long, distinctly clubbed distally, bearing a brush of curved sensilla chaetica apically; antennal groove reaching flagellomeres 2-3. AR 1.15. Thorax. Lobes of antepronotum not gaping with dome-like median area; lateral antepronotals 7 including 5 located distally and 2 vestigial located medially; acrostichals 18 in 1 row; dorsocentrals 9-10 in 1 row; prealars 3, supraalars absent. Humeral pit (Fig. 9) strongly elongate, ellipsoidal with narrowed distal part, a distinct smaller separate oval pit is located below. Scutellum with 8 uniserial setae. Wing. Brachiolum with 3 setae. Distribution of setae on veins: $\mathrm{R}$, $7-8 ; \mathrm{R}_{1}, 0-1 ; \mathrm{R}_{4+5}, 1-2$; other veins bare. Squama with 7 setae in 1 row. Legs. Length $(\mu \mathrm{m})$ of tibial spurs of: PI, distinctly spiniforme, 60; PII, 25 and 35; PIII, 65 and 30; longest seta of tibial comb $65 \mu \mathrm{m}$ long. Sensilla chaetica present in low number (proximally and distally) on tarsomeres $\mathrm{ta}_{1}-\mathrm{ta}_{5}$ of PI, PII and PIII. Length $(\mu \mathrm{m})$ and proportions of prothoracic (PI), mesothoracic (PII) and metathoracic (PIII) legs as in Table 1.

Abdomen. Hypopygium in dorsal and ventral view (Figs. 14-15). Tergite IX nearly semicircular, with a weak median hump, which is clearly visible in lateral view (Fig. 12). Anal point about $45 \mu \mathrm{m}$ long, triangular, large at base, uniformly narrowed distally and ending with a distinct rounded apex; 12-14 setae are present laterally (6-7 on each side). Latero-sternite IX with 5 setae. Transverse sternapodeme and phallapodeme as in Figs. 15-16. Virga absent. Gonocoxite about $250 \mu \mathrm{m}$ long, maximum width 25-30 $\mu \mathrm{m}$, distinctly truncate apically. Superior volsella (Figs. 15-16) widely projecting downwards and ending with a rounded apex; inferior volsella large and lobe-like dorsally with a long finger-like apex, ventral side trianglelike. Gonostylus in dorsal, lateral and ventral view (Figs. 14, 19-21) $85 \mu \mathrm{m}$ long, $25 \mu \mathrm{m}$ maximum width, posterior margin swollen medially and abruptly narrowing apically, anterior surface with 2 rows of setae clearly visible at obtuse angle; crista dorsalis located distally close to the megaseta, short tooth-like and only visible in right-angle view (Figs. 20-21). 


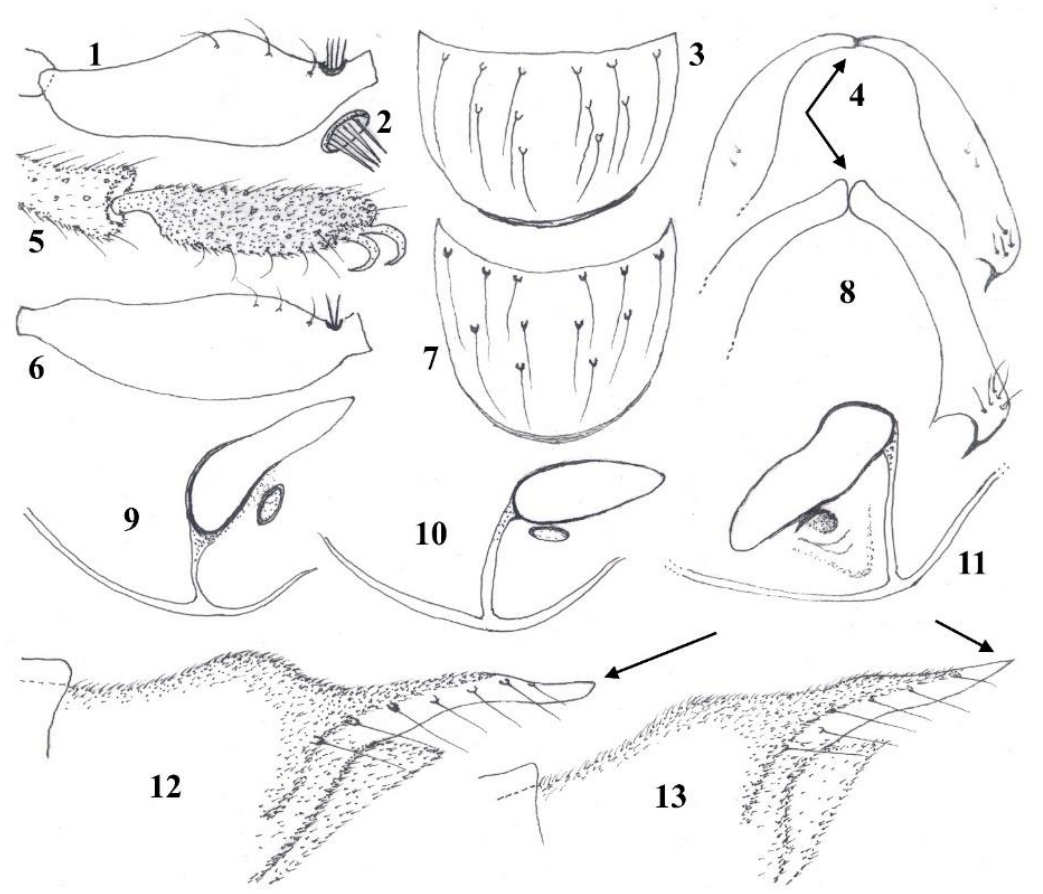

Figs. 1-13. Male imago of Rheocricotopus (s. str.) spp. R. costai sp. n.: palpomere 3 (1); with details of sensilla coeloconica (2); clypeus (3); lobes of antepronotum (4); apex of tarsomeres 4 and 5 (5). Rheocricotopus effusus: palpomere 3 (6); clypeus (7); lobes of pronotum (8). Humeral pit of: $R$. costai sp. n., holotype (9); R. effusus (10); R. pyrenaeus sp. n. (11). Lateral view of tergite IX and anal point of: R. costai sp. n. (12); R. effusus (13).

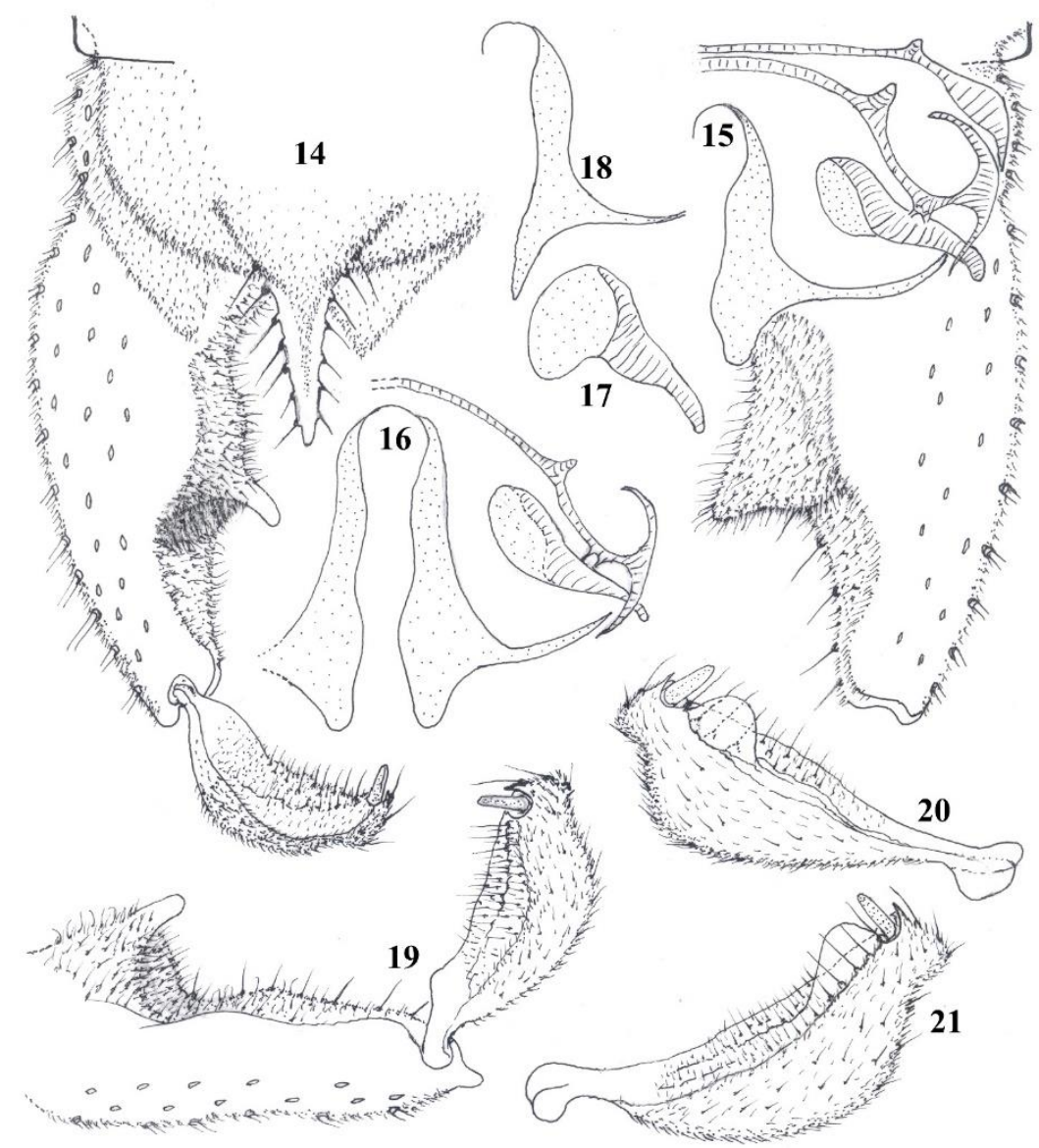

Figs. 14-21. Male imago of Rheocricotopus (s. str.) spp. R. costai sp. n.: hypopygium in dorsal (14) and ventral view (15), with tergite and anal point removed); superior volsella, sternapodeme and phallpodeme (16). R. effusus: phallapodeme (17); superior volsella (18). $R$. costai sp. n.: gonocoxite and gonostylus in lateral view (19); gonostylus (right angle, dorsal, 20 and ventral, 21). 


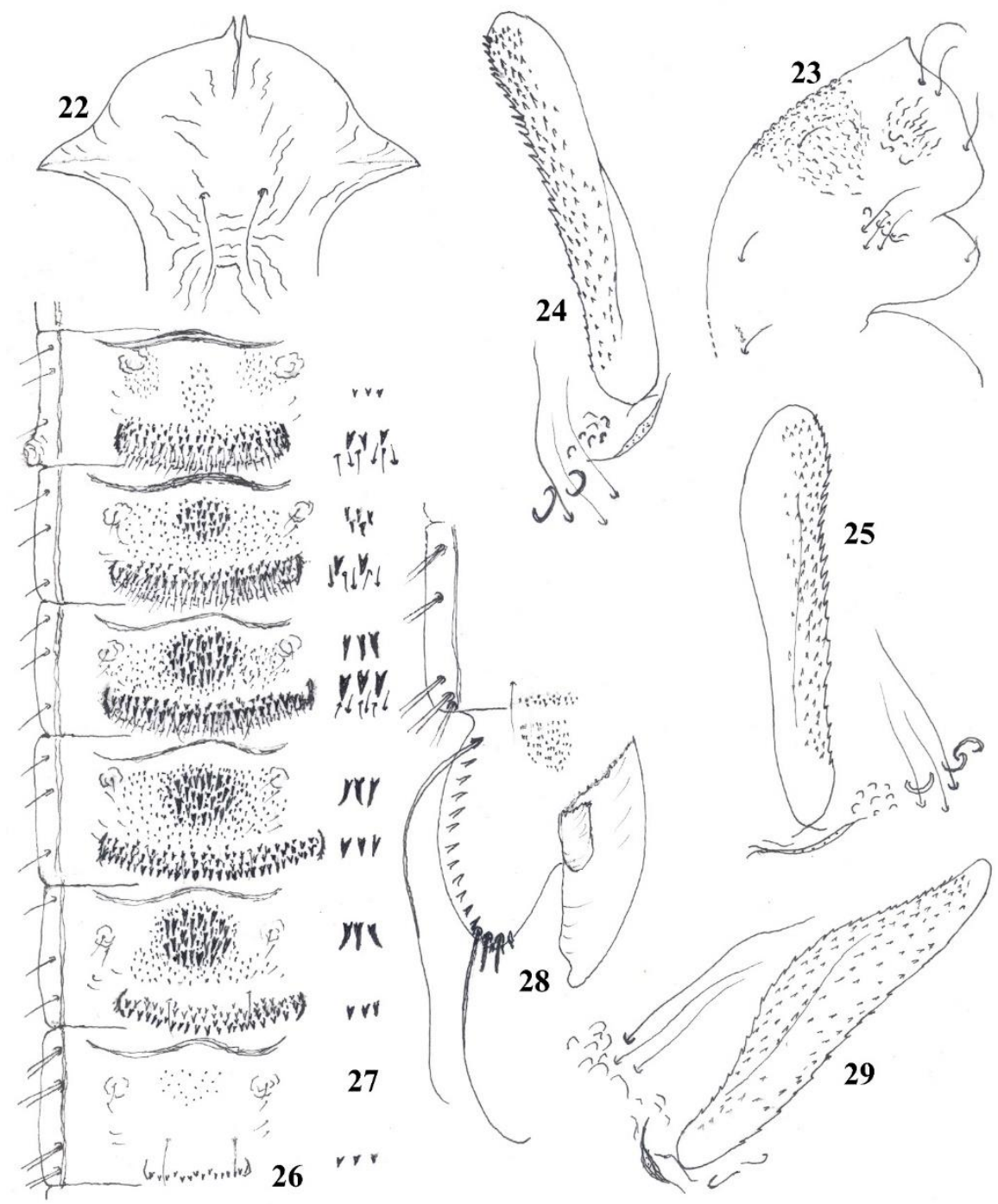

Figs. 22-29. Pupal exuviae of Rheocricotopus (s. str.) spp. R. costai sp. n.: frontal apotome (22); cephalothorax (23); two aspects of thoracic horn (24-25); distribution pattern of armament and chaetotaxy of abdominal segments II-VII (26); details of armament on tergites II-VII and conjunctives (27); tergite VIII and anal segment (28). R. effusus: thoracic horn (29).

\section{Pupal exuviae}

$(\mathrm{n}=4: 2$ males and 2 females; Figs. 22-28)

Total length 3.60-3.65 mm. Colouration brownish in general. Frontal apotome brown and weakly wrinkled. Anterio-median area of cephalothorax including the thoracic suture markedly rugulose and wrinkled; blackish shading present near the base of thoracic horn and wing sheath; outer and inner margin of antennal sheath brownish. Abdomen brown yellowish, lateral margin of segments I-VIII dark brown. Anal lobe and genital sac brown yellowish. Cephalothorax as in Figs. 22-23. Frontal apotome (Fig. 22) broadly semicircular, lateral margin with a distinct triangular expansion, frontal setae 95-100 $\mu \mathrm{m}$ long, distance between frontal setae $25 \mu \mathrm{m}$. Thorax. Median antepronotals are nearly subequal (160 and 155 $\mu \mathrm{m}$ long), 1 lateral antepronotal $105 \mu \mathrm{m}$ long; prealars, 1 vestigial seta; precorneals 190,180 and $125 \mu \mathrm{m}$ long, inserted long distance from base of thoracic horn.
Thoracic horn (Figs. 24-25) about 320-330 $\mu \mathrm{m}$ long, maximum width $40-50 \mu \mathrm{m}$, finger-like, linearly elongated and strongly toothed on one side, teeth becoming gradually larger towards apex. Dorsocentrals $\mathrm{Dc}_{1}-\mathrm{Dc}_{4}$ (Fig. 23) include: 3 sub-equal setae $\left(\mathrm{Dc}_{1}, \mathrm{Dc}_{2}\right.$ and $\mathrm{Dc}_{4}=$ $55 \mu \mathrm{m}$ long), $\mathrm{Dc}_{3} 20 \mu \mathrm{m}$ long; distance $(\mu \mathrm{m})$ between: $\mathrm{Dc}_{1}$ to $\mathrm{Dc}_{2} 185, \mathrm{Dc}_{2}$ to $\mathrm{Dc}_{3} 130, \mathrm{Dc}_{3}$ to $\mathrm{Dc}_{4} 15$.

Abdomen. Armament, chaetotaxy, distribution pattern of shagreen and details of armament on tergites IIVII as in Figs. 26-27. All pleurae and tergite I bare. Pedes spurii A present on sternites IV-VI, pedes spurii B present only on segment II. Caudal transverse rows of posteriorly projecting stout spines (3-4 rows) present on tergites IIVI, those on tergites IV-V are the widest $(350-400 \mu \mathrm{m})$; caudal transverse rows (2-3) of orally and posteriorly directed pins are restricted to conjunctives of tergites IIIV, those on tergite IV are the widest $(390 \mu \mathrm{m})$; caudal transverse rows of short spines and spinules (about 120$150 \mu \mathrm{m}$ wide) are present on tergites VII-VIII. 
Table 1. Male adult of Rheocricotopus costai sp. n. Length $(\mu \mathrm{m})$ and proportions of prothoracic (PI), mesothoracic (PII) and metathoracic (PIII) legs.

\begin{tabular}{|c|c|c|c|c|c|c|c|c|c|c|c|}
\hline & fe & ti & ta1 & ta2 & ta3 & ta4 & ta5 & LR & BV & SV & BR \\
\hline PI & 585 & 690 & 535 & 275 & 225 & 160 & 115 & 0.78 & 2.34 & 2.38 & 2.10 \\
\hline PII & 735 & 685 & 365 & 175 & 145 & 105 & 90 & 0.53 & 3.47 & 3.89 & 2.60 \\
\hline PIII & 1190 & 1360 & 730 & 265 & 215 & 125 & 95 & 0.54 & 4.69 & 3.49 & 3.40 \\
\hline
\end{tabular}

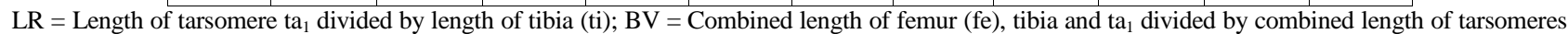

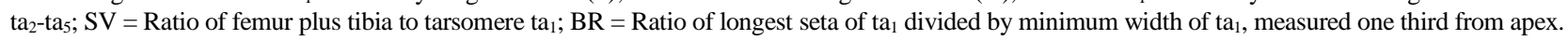

Distribution pattern, shape and size of circular median patch of stout spines on tergites IV-VI as in Figs. 26-27: those on tergites V-VI are subequal in size, more extensive and armed with much larger spines, longest spines $18-20 \mu \mathrm{m}$ long; median patch on tergite III is smaller and armed with short spinules, longest one 10-12 $\mu \mathrm{m}$ long; caudal transverse rows (1-2) of short spines present on tergites VII-VIII (maximum width 120-150 $\mu \mathrm{m})$. Number and distribution pattern of lateral setae and lamelliform setae (taeniae) on segments I-VIII as in Fig. 26: lateral setae on segments I-VI $(1,3,3,3,3,3)$; taeniae on segments VII-VIII $(4,5)$. Anal segment (Fig. 28): anal lobe $225 \mu \mathrm{m}$ long, $250 \mu \mathrm{m}$ maximum width, fringe with 15-17 taeniae; genital sac 190-200 $\mu \mathrm{m}$ long, overreaching apical margin of anal lobe by $35-40 \mu \mathrm{m}$; macrosetae $310-$ $325 \mu \mathrm{m}$ long, curved and pointed apically.

\section{Larva}

Known but not described.

\section{Rheocricotopus (Rheocricotopus) pyrenaeus sp. $\mathbf{n}$.}

\section{LSID:urn:1sid:zoobank.org:act:3875E849-80A2-4710- AE18-551F2D573119}

\section{Material examined}

Holotype. Continental France. 1 male pharate adult, leg. J. Moubayed-Breil, Mantet Nature Reserve (Eastern Pyrenees), upper basin of 'Font des Soques', glacial springs and stream, altitude $2000 \mathrm{~m},\left(42^{\circ} 28^{\prime} 38^{\prime \prime} \mathrm{N}\right.$, $\left.02^{\circ} 18^{\prime} 26^{\prime \prime} \mathrm{E}\right), 05.08 .2010$. Environmental data of aquatic habitat: crystalline water, conductivity $30-40 \mu \mathrm{S} / \mathrm{cm}, \mathrm{pH}$ 5.5-5.7; temperature $6-12^{\circ} \mathrm{C}$.

Paratypes (all leg. J. Moubayed-Breil). 3 pharate adults (1 male and 2 females), 1 pupal exuviae, same locality and data as for holotype. Callau acid springs and peat bogs at Mantet Nature Reserve, 1 male adult and 1 male pharate adult, alt. 2000-2300 m, 05.08.2010. Environmental data of aquatic habitat: crystalline water, conductivity 20-30 $\mu \mathrm{S} / \mathrm{cm}, \mathrm{pH}$ 5.5-5.7; temperature $6-12^{\circ} \mathrm{C}$.

Holotype (male adult + its pupal exuvie, on 1 slide) is deposited in the collections of the National Museum of Ireland, Kildare Street, Dublin 2, Ireland. Paratypes are deposited in the senior author's collection.

Type material was preserved in $80 \%$ ethanol, and later mounted in polyvinyl lactophenol. For each adult, the head, thorax and abdomen were cleared in $90 \%$ lactic acid, then washed in $70 \%$ ethanol before mounting on slides.

Etymology: The new species is named 'pyrenaeus' after the Pyrenees mountains where its geographical distribution is currently restricted to the protected area of the 'Mantet Nature Reserve', (located in the Eastern Pyrenees of France), which covers glacial springs, peat bogs and pristine cold streams.

\section{Diagnostic characters}

Rheocricotopus pyrenaeus sp. n. directly keys near both $R$. reduncus (Finland, Norway and Russian Far East) and $R$. tchernovskii (Russian Far East) in the effususgroup based, on the following two main imaginal and pupal characters: distal part of superior volsella markedly turned over and curved inwards; median circular patch of spinules on tergite IV much smaller than those on tergites V-VI. However, this new species can be separated from other related members of the effusus-group in having:

- male adult. Coronal area with 4 coronals (2 setae on each side); lobes of antepronotum thick and widely gaping medially; distal half of tarsomere tas of PI, PII and PIII blackish; humeral pit ellipsoidal, moderately elongate, larger in proximal part with a distinct smaller half ovallike pit below; tergite IX bearing a distinct hump medially, which is clearly visible in lateral view; apex of anal point sharply pointed; superior volsella broad, noselike apically, distal part distinctly projecting and turned over inwards; dorsal side of inferior volsella triangular with large thumb-like apex, ventral side triangular; posterior side of gonostylus swollen medially in both lateral view and at right-angles, distal part constricted near the apex; crista dorsalis clearly visible in lateral and at right-angles, widely extended distally from middistance till apex, semicircular and occupying 70 to $80 \%$ of the total length of gonostylus.

- pupal exuviae. Frontal apotome nearly semicircular, anterior half covered with faint and fine wrinkles; thoracic horn markedly clubbed and toothed on one side. Circular median patch of spines present on tergites IV-VI; patch on tergite IV distinctly smaller and armed with short spinules; patches on tergites V-VI are subequal, more extensive and armed with much longer and larger spines.

\section{Male imago}

$(\mathrm{n}=3: 1$ male adult and 2 male pharate adults; Figs. 30, 32-46)

$$
=\text { "R. }(R h .) \text { sp. 1" in Moubayed-Breil \& Ashe (2016) }
$$

Large sized species, slightly larger than $R$. costai sp. n. Total length 3.60-3.65 mm. Wing length $1.80-1.85 \mathrm{~mm}$. Colouration variable from dark brown to blackish in general, especially on the thorax, legs and tergites. Head, antenna and halters dark brown. Thorax dark brown; mesonotal stripes blackish and distinct; humeral pit 


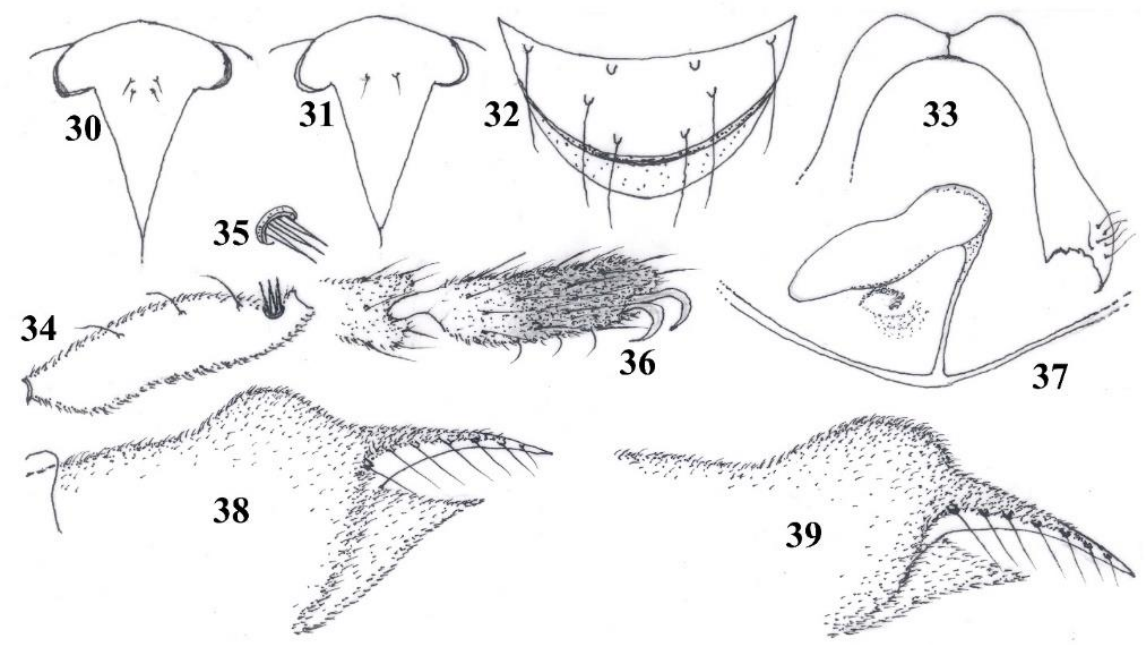

Figs. 30-39. Male imago of Rheocricotopus (s. str.) spp. vertex with coronal area of: R. pyrenaeus sp. n. (30); R. costai sp. n. (31). R. pyrenaeus sp. n.: clypeus (32); lobes of antepronotum (33); palpomere 3 (34) with details of sensilla coeloconica (35); tarsomere 5 of PI (36); humeral pit, holotype (37); two aspects of tergite IX and anal point in lateral view (38-39).

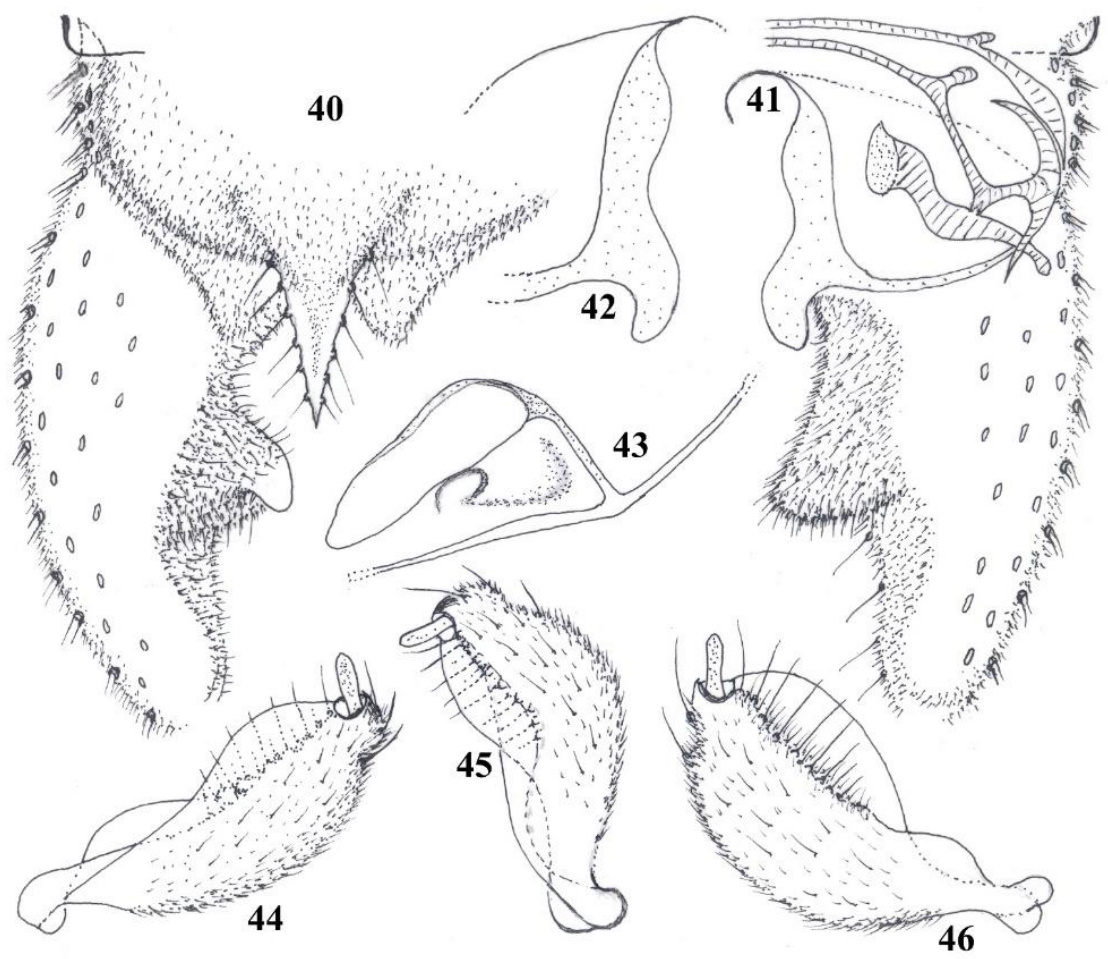

Figs. 40-46. Male imago of Rheocricotopus (s. str.) pyrenaeus sp. n.: hypopygium in dorsal (40) and ventral view (41 with tergite and anal point removed); superior volsella (42); humeral pit, paratype (43); gonostylus in dorsal (44), lateral (45) and ventral view (46).

brownish. Legs dark brown, distal half of tarsomeres ta of PI, PII and PIII distinctly blackish. Abdominal tergites and anal segment dark brown. Head. Eyes hairy, elongated vertically. Coronal area (Fig. 30) with 4 coronals (2 setae on each side); Temporal setae 7, including 5 inner and 2 outer verticals, postorbitals absent. Clypeus (Fig. 32) semicircular, bearing 8 setae in 3 rows. Palp 5-segmented, length $(\mu \mathrm{m})$ of palpomeres 1-5: 30, 55, 80, 105, 115; third palpomere (Fig. 34) with 3 sensilla clavata and 3 sensilla coeloconica (Fig. 35) located distally. Antenna $855 \mu \mathrm{m}$ long; last flagellomere $390 \mu \mathrm{m}$ long, distinctly clubbed distally, apex with a brush of curved sensilla chaetica; segments 6-10 subequal (about $45 \mu \mathrm{m}$ long); length $(\mu \mathrm{m})$ of segments: $70,75,30,30,35$, $45,45,45,45,45,390$; antennal groove reaching segments 2-3. AR 0.84. Thorax. Lobes of antepronotum (Fig. 33) gaping and widely separated; lateral antepronotals 6 located distally; acrostichals 25-27 in 1-2 rows, reaching half of thorax; dorsocentrals $13-15$ in 1-2 rows; prealars and supraalars absent. Humeral pit (Figs. 37, 43) moderately elongate, ellipsoid with broadened proximal part, a distinct smaller separate half oval-like pit is located below. Scutellum with 8 uniserial setae. Wing. Brachiolum with 2 setae. Distribution of setae on veins: 
Table 2. Male adult of Rheocricotopus pyrenaeus sp. n. Length $(\mu \mathrm{m})$ and proportions of prothoracic (PI), mesothoracic (PII) and metathoracic (PIII) legs.

\begin{tabular}{|c|c|c|c|c|c|c|c|c|c|c|c|}
\cline { 2 - 12 } \multicolumn{1}{c|}{} & $\mathbf{f e}$ & $\mathbf{t i}$ & ta1 & ta2 & ta3 & ta4 & ta5 & LR & BV & SV & BR \\
\hline PI & 565 & 615 & 445 & 280 & 185 & 125 & 100 & 0.72 & 2.36 & 2.65 & 1.78 \\
\hline PII & 640 & 590 & 325 & 170 & 140 & 75 & 75 & 0.55 & 3.38 & 3.78 & 2.00 \\
\hline PIII & 665 & 695 & 390 & 220 & 180 & 90 & 90 & 0.56 & 3.02 & 3.49 & 2.40 \\
\hline
\end{tabular}

$\mathrm{R}, 7-8 ; \mathrm{R}_{1}, 2 ; \mathrm{R}_{2+3}, 2$; remaining veins bare. Squama with 5-7 setae in 1 row. Legs. Tarsomere ta (Fig. 36) of PI, PII, PIII blackish in its distal half; tarsomeres ta and $\mathrm{ta}_{5}$ of PII and PIII are equal in size (respectively: 75 and 90 $\mu \mathrm{m}$ long). Length $(\mu \mathrm{m})$ of tibial spurs of: PI, distinctly spiniforme, 40; PII, 25 and 20; PIII, 50 and 25; longest seta of tibial comb $55 \mu \mathrm{m}$ long. Sensilla chaetica present in low number (proximally and distally) on tarsomeres $\mathrm{ta}_{1}$-ta $\mathrm{ta}_{5}$ of PI, PII and PIII. Length $(\mu \mathrm{m})$ and proportions of prothoracic (PI), mesothoracic (PII) and metathoracic (PIII) legs as in Table 2.

Abdomen. Hypopygium in dorsal and ventral view (Figs. 40-41). Tergite IX semicircular, with a distinct rounded median hump, which is clearly visible in lateral view (Figs. 38-39). Anal point about 45-50 $\mu \mathrm{m}$ long, triangular and slightly curved downwards, large at base and uniformly narrowed distally with a sharp pointed apex; 12 setae are present laterally (6 on each side). Latero-sternite IX with 6 setae. Transverse sternapodeme and phallapodeme as in Fig. 41. Virga absent. Gonocoxite about $265 \mu \mathrm{m}$ long, maximum width 50-55 $\mu \mathrm{m}$, apex rounded. Superior volsella (Figs. 41-42) broadly projecting downwards and inwardly turned over distally, apex distinctly rounded. Inferior volsella large, lobe-like dorsally, with a large thumb-like apex, ventral side trianglelike. Gonostylus in dorsal, lateral and ventral view (Figs. 44-46) $85 \mu \mathrm{m}$ long, $33 \mu \mathrm{m}$ maximum width, posterior margin swollen medially and abruptly narrowing apically; crista dorsalis clearly visible in both lateral and right-angle views, starting at mid-distance and widely extended distally till apex of gonostylus, semicircular and occupying 70 to 80 $\%$ of the total length of gonostylus.

\section{Female imago}

$(\mathrm{n}=2: 1$ adult and 1 pharate adult; Figs. 47-55)

Large sized species. Total length 3.70-3.75 mm. Wing length 1.85-1.90 mm. Colouration dark brown to blackish including head, antenna, thorax and tergites. Head and halters dark brown; antenna dark brown, last flagellomere blackish (Fig. 49); thorax dark brown, mesonotal stripes blackish and distinct; humeral pit brownish. Legs brown to dark brown, distal half of tarsomeres 5 of PI, PII and PIII blackish. Abdominal tergites and anal segment dark brown to blackish. Head. Eyes hairy, elongated vertically. Coronal area, as in the male, with 4 coronals ( 2 setae on each side); Temporal setae 9, including 7 inner and 2 outer verticals, postorbitals absent. Palp 5-segmented, length $(\mu \mathrm{m})$ of palpomeres 1-5: 45, 75, 105, 125, 165; distal part of third palpomere (Fig. 47) with 3 sensilla clavata, sensilla coeloconica absent. Clypeus (Fig. 48) semicircular, bearing 12 setae in 3 rows. Antenna $305 \mu \mathrm{m}$ long; last flagellomere $120 \mu \mathrm{m}$ long, proximal part slightly clubbed, distal part narrowing, surface including apex with numerous sensilla chaetica, antennal groove reaching segment 4. AR 0.65. Thorax. Lobes of antepronotum (Fig. 50) gaping and widely separated as in the male; lateral antepronotals 5 located distally; acrostichals 14 in 1-2 rows, reaching half of thorax; dorsocentrals 12-13 in 1-2 rows; prealars 4, supraalars absent; humeral pit (Fig. 51) moderately elongate, ellipsoid with broadened proximal part, a distinct smaller separate oval pit is located below. Scutellum with 8 uniserial setae. Wing. Brachiolum with 1 seta. Distribution of setae on veins: $\mathrm{R}, 12 ; \mathrm{R}_{1}, 13 ; \mathrm{R}_{4+5}, 20-25$; remaining veins bare. Squama with $9-13$ setae in 1 row. Legs. Distal half of tarsomere ta 5 of PI, PII and PIII blackish; tarsomere ta 4 and ta 5 of PIII are equal in size (135 $\mu \mathrm{m}$ long). Length $(\mu \mathrm{m})$ of tibial spurs of: PI, distinctly spiniforme, 45; PII, 30 and 25; PIII, 90 and 30; longest seta of tibial comb $65 \mu \mathrm{m}$ long. Sensilla chaetica present in low number on tibia and tarsomeres ta $_{1}-$ ta $_{5}$ of PI, PII and PIII. Length (in $\mu \mathrm{m}$ ) and proportions of prothoracic (PI), mesothoracic (PII) and metathoracic (PIII) legs as in Table 3.

Genitalia in dorsal and ventral view as illustrated in Fig. 52. Notum 130-135 $\mu \mathrm{m}$ long. Gonapophysis VIII including ventrolateral, dorsomesal and apodeme lobe (Figs. 52-54): apodemelobe (Fig. 53) inversed S-like, base crotchet-like; dorsomesal lobe (Fig. 54) conspicuous, proximal part slightly swollen, distal part linear; ventrolateral lobe (Fig. 52) projecting inwards apically. Sternite VIII with 22 setae (11 on each side of gonapophysis VIII). Seminal capsules (Fig. 52) $125 \mu \mathrm{m}$ long, $85 \mu \mathrm{m}$ wide, pearl-like, sclerotized part occupying basal, lateral and apical part, ducts with loops and separate openings. Tergite IX and gonocoxite (Fig. 55): gonocoxite weakly swollen with 9-10 setae; tergite IX nearly semicircular with convex anterior margin, distinctly divided in 2 oval lobes, bearing 20-22 setae (1011 on each side), posterior margin concave. Cercus 70-80 $\mu \mathrm{m}$ long.

\section{Pupal exuviae}

$(\mathrm{n}=4: 2$ males and 2 females; Figs. 60-66)

Total length 3.65-3.75 mm. General colouration brownish. Frontal apotome brown, anterior half covered with fine wrinkles. Anterio-median area of cephalothorax and suture of thorax markedly rugulose and wrinkled; base of thoracic horn and wing sheath with blackish shading; outer and inner margin of antennal sheath brownish. Abdomen brown yellowish, lateral margin of segments I-VIII brownish. Anal lobe and genital sac 


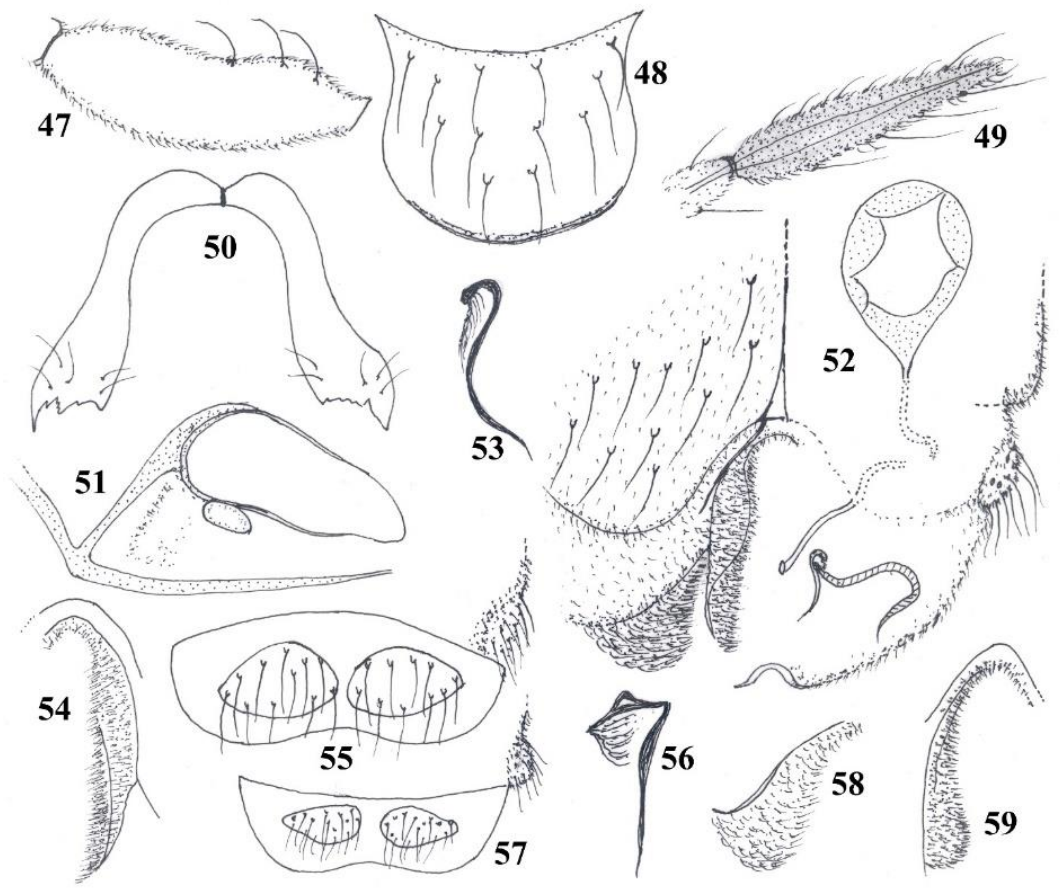

Figs. 47-59. Female imago of Rheocricotopus (s. str.) spp. R. pyrenaeus sp. n.: tarsomere 3 (47); clypeus (48); last flagellomere of antenna (49); lobes of antepronotum (50); humeral pit (51); genitalia, dorsal and ventral view (52) including gonapophysis VIII, sternite VIII, seminal capsule and right gonocoxite; apodeme lobe (53); dorsomesal lobe (54); tergite IX (55). R. effusus: apodeme lobe (56); tergite IX (57); ventrolateral lobe (58); dorsomesal lobe (59).

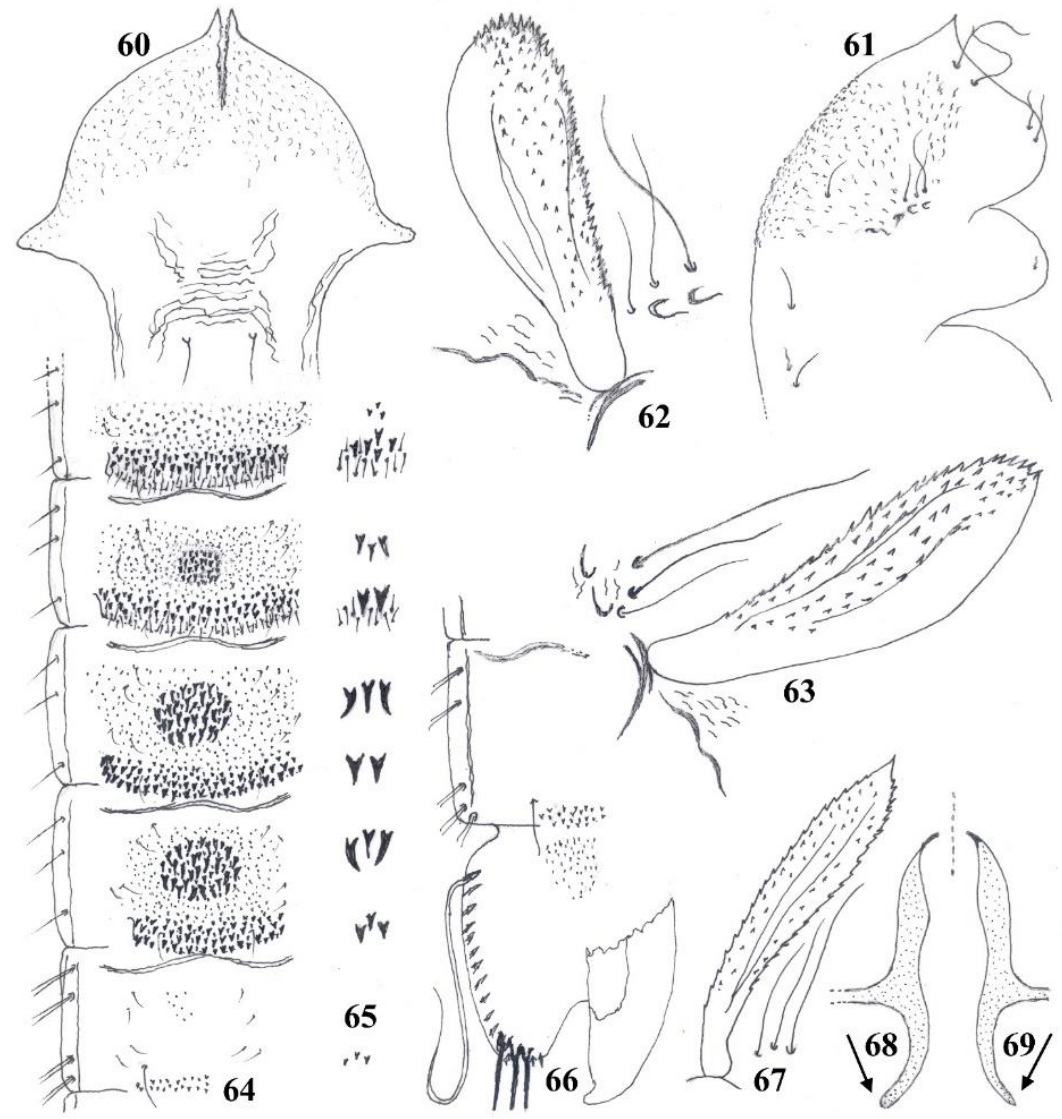

Figs. 60-69. Pupal exuviae of Rheocricotopus (s. str.) spp. R. pyrenaeus sp. n.: frontal apotome (60); cephalothorax (61); two aspects of thoracic horn (62-63); distribution pattern of armament and chaetotaxy of abdominal segments III-VII (64); details of armament on tergites III-VII and conjunctives (65); tergite VIII and anal segment (66). Thoracic horn of $R$. tchernovskii (67, after Makarchenko \& Makarchenko 2005). Superior volsella of $R$. reduncus (68, after Sæther \& Schnell 1988) and R. tchernovskii (69, after Makarchenko \& Makarchenko 2005). 
Table 3. Female adult of Rheocricotopus pyrenaeus sp. n. Length $(\mu \mathrm{m})$ and proportions of prothoracic (PI), mesothoracic (PII) and metathoracic (PIII) legs.

\begin{tabular}{|c|c|c|c|c|c|c|c|c|c|c|c|}
\hline & fe & ti & ta1 & ta2 & ta3 & ta4 & ta5 & LR & BV & SV & BR \\
\hline PI & 1025 & 1150 & 695 & 400 & 290 & 200 & 140 & 0.60 & 2.79 & 3.13 & 2.67 \\
\hline PII & 1080 & 1225 & 720 & 410 & 285 & 175 & 150 & 0.59 & 2.97 & 3.20 & 2.00 \\
\hline PIII & 1010 & 1030 & 460 & 270 & 210 & 135 & 135 & 0.45 & 3.33 & 4.43 & 2.00 \\
\hline
\end{tabular}

brown yellowish. Cephalothorax as in Figs. 60-61. Frontal apotome (Fig. 60) semicircular, lateral margin bearing a distinct triangular expansion, frontal setae 80-85 $\mu \mathrm{m}$ long, distance between frontal setae $20 \mu \mathrm{m}$. Thorax. Median antepronotal nearly subequal (170 and $165 \mu \mathrm{m}$ long), 2 lateral antepronotals each $105 \mu \mathrm{m}$ long; prealars, vestigial; precorneals 195, 165 and $85 \mu \mathrm{m}$ long. Thoracic horn (Figs. 62-63) about $300 \mu \mathrm{m}$ long, maximum width 20-25 $\mu \mathrm{m}$, distinctly clubbed and toothed on one side. Dorsocentrals $\mathrm{Dc}_{1}-\mathrm{Dc}_{4}$ (Fig. 61) consist of: 3 sub-equal setae $\left(\mathrm{Dc}_{1}, \mathrm{Dc}_{2}\right.$ and $\mathrm{Dc}_{4}=55-60 \mu \mathrm{m}$ long), $\mathrm{Dc}_{3} 25 \mu \mathrm{m}$ long; distance $(\mu \mathrm{m})$ between: $\mathrm{Dc}_{1}$ to $\mathrm{Dc}_{2} 110, \mathrm{Dc}_{2}$ to $\mathrm{Dc}_{3}$ 40-50, $\mathrm{Dc}_{3}$ to $\mathrm{Dc}_{4} 15-20$.

Abdomen. Armament, chaetotaxy and distribution pattern of shagreen with details of armament on tergites III-VII as in Figs. 64-65. All pleurae and tergite I bare. Pedes spurii A present on sternites IV-VI, pedes spurii B present only on segment II. Caudal transverse rows of posteriorly projecting stout spines (3-4 rows) present on tergites II-VI, those on tergites IV-V are the widest (360$400 \mu \mathrm{m})$; caudal transverse rows (2-3) of orally and posteriorly directed pins are restricted to conjunctives of tergites II-IV, those on tergite IV are the widest $(380 \mu \mathrm{m})$; caudal transverse rows of short spines and spinules (about 120-150 $\mu \mathrm{m}$ wide) are present on tergites VII-VIII. Distribution pattern, shape and size of circular median patch of stout spines on tergites IV-VI as in Figs. 64-65: those on tergites $\mathrm{V}$-VI are subequal in size, more extensive and armed with much larger spines, longest spines $18-20 \mu \mathrm{m}$ long; median patch on tergite IV is smaller and armed with short spines and spinules, longest one 10-12 $\mu \mathrm{m}$ long; caudal transverse rows (1-2) of short spines present on tergites VII-VIII (maximum width 120$150 \mu \mathrm{m}$ ). Number and distribution pattern of lateral setae and lamelliform setae (taeniae) on segments I-VIII as in Fig. 64: lateral setae on segments I-VI (1, 3, 3, 3, 3, 3); taeniae on segments VII-VIII $(4,5)$. Anal segment (Fig. 66): anal lobe $250 \mu \mathrm{m}$ long, $285 \mu \mathrm{m}$ maximum width, fringe with 14-16 taeniae; genital sac 190-200 $\mu \mathrm{m}$ long, overreaching apical margin of anal lobe by $40 \mu \mathrm{m}$; macrosetae 315-325 $\mu \mathrm{m}$ long curved and pointed apically.

\section{Larva}

Known but not described.

\section{Taxonomic position}

Though $R$. costai sp. n. apparently shows a closely phylogenetic relationships with the effusus-group (shape of the humeral pit and gonostylus), some other relevant specific characters found in the male adult and exuviae (lobes of antepronotum thin; apex of anal point rounded; distal part of superior volsella short and widely projecting downwards; tergite III of exuviae bearing a distinct median circular patch of spinules) allowed us to consider this new species as a separate local 'Pyreneo-corsican element'. Nevertheless, due to some specific characters found in the male adult and exuviae of $R$. pyrenaeus $\mathrm{sp} . \mathrm{n}$. (distal part of superior volsella markedly inwardly turned over distally; circular median patch of spines on tergite IV distinctly smaller than those on tergites V-VI), this new species keys near both $R$. reduncus (known from Norway) and $R$. tchernovskii (known from Far East Russia), based in particular, on the elongate distal part of the superior volsella which is markedly turned over inwards. Therefore, a fourth additional group within the subgenus Rheocricotopus, the 'reduncus-group', could be created to include the three following species: $R$. reduncus, $R$. tchernovskii and R. pyrenaeus sp. $\mathrm{n}$.

However, the specific characters found in the male and female adults and pupal exuviae will separate the two new described species from other related known members of the effusus-group, on the basis of the following combination of characters.

\section{R. costai sp. n.}

- Male adult. Palpomere 3 with 3 sensilla coeloconica (Fig. 1), but only 2 in R. effusus (Fig. 6); clypeus and lobes of antepronotum (Figs. 3-4) are differently figured in $R$. effusus (Figs. 7-8); humeral pit (Fig. 9) is distinctly elongate and narrowed distally, which is broad ellipse-like in R. effusus (Fig. 10; Lehmann 1969, Fig. 13a); lateral view of both tergite IX and anal point (Fig. 12) clearly reveals the presence of a distinct rounded hump on tergite IV and anal point with rounded apex, while a lower hump and a sharply pointed apex are observed in R. effusus (Fig. 13); distal part of superior volsella not narrowing, short and broadly projecting downwards with a rounded apex (Figs. 15-16), is projecting outwards in R. tamahumeralis Sasa, 1981, which is only known from Japan (Sasa 1981, Fig. 19I), or moderately longer, gradually narrowing and bearing a pointed apex in R. effusus (Fig. 18; Albu 1968, Fig. 9; Lehmann 1969, Fig. 5; Langton \& Pinder 2007, Fig. 189C; Makarchenko \& Makarchenko 2005, Figs. 11$14)$; inferior volsella with a distinct rounded apex, while is notched apically in $R$. tamahumeralis (Sasa 1981, Fig. 19J); phallpodeme (Fig. 15) is differently shaped in $R$. effusus (Fig. 17); crista dorsalis (Figs. 20-21) short, toothlike and located close to the megaseta, is lower and much wider in R. effusus (Lehmann 1969, Fig.5; Langton \& Pinder 2007, Figs. 72D, 189C).

- Pupal exuviae. Frontal apotome (Fig. 22) semicircular, is nearly triangular in $R$. effusus (Coffman et al. 1986, Fig. 9.59A); thoracic horn finger-like and toothed on one side 
(Figs. 24-25), is differently illustrated in both $R$. tamahumeralis (Sasa 1981, Fig. 20A) and R. effusus (Fig. 29; Coffman et al. 1986, Fig. 9.59C; Langton 1991, Fig. 45c); small circular median patch of spinules distinctly present on tergite III (Fig. 26), is apparently lacking in (almost) all members of the effusus-group (Lehmann 1969, Fig. 21b; Coffman et al. 1986, 9.59D; Langton 1991, Figs. $45 \mathrm{~b}$ ) except in $R$. tamahumeralis (species only known from Japan) which bears a 'weakly-defined' median patch of spinules on tergite III (Sasa 1981, Fig. 20B).

\section{R. pyrenaeus sp. $\mathbf{n}$.}

Male and female adults and pupal exuviae of this new species can be separated from its two closely related species $R$. reduncus and $R$. tchernovskii, and other members of the effusus-group by a combination of differentiating characters.

- Male adult. Clypeus and lobes of antepronotum (Figs. 32-33) are differently figured in $R$. effusus (Figs. 7-8); humeral pit (Figs. 11, 37, 43) is strongly reduced in both $R$. reduncus and $R$. tchernovskii and differently figured in $R$. effusus (Fig. 10); tergite IX and anal point in lateral view (Figs. 38-39) are differently shaped in R. effusus (Fig. 13); distal part of superior volsella short and broadly turned over inwards with a rounded apex (Figs. 41-42), while is much longer and gradually narrowing in both $R$. reduncus and $R$. tchernovskii (Figs. 68-69; Makarchenko \& Makarchenko 2005, Figs. 21-22; Sæther \& Schnell 1988, Fig. 1D); crista dorsalis largely extended (Figs. 44-46), is much shorter and lower in R. effusus (Lehmann 1969, Fig. 5) and entirely absent in both $R$. reduncus and $R$. tchernovskii (Makarchenko \& Makarchenko 2005, Fig. 22; Sæther \& Schnell 1988, Fig. 1D).

- Female adult. Lobes of antepronotum (Fig. 50) are similarly shaped as in the male adult; distal part of the apodeme lobe inversed S-like in shape (Fig. 53), while is linear in R. effusus (Fig. 56; Sæther 1986, Fig. 22E); dorsomesal and ventrolateral lobes (Figs. 52, 54) are differently figured in $R$. effusus (Figs. 58-59; Sæther 1986, Fig. 22E); gonocoxite and tergite IX (Figs. 52, 55) are differently illustrated in R. effusus (Fig. 57; Sæther 1986, Fig. 22D).

- Pupal exuviae. Thoracic horn (Figs. 62-63) club-like and toothed on one side, while is linearly elongated and toothed on each side in both $R$. reduncus (Sæther \& Schnell 1988, Fig. 2C) and R. tchernovskii (Fig. 67; Makarchenko \& Makarchenko 2005, Fig. 24); small circular median patch of spines on tergite IV (Fig. 64), similarly present in both $R$. reduncus (Sæther \& Schnell 1988, Fig. 2E) and R. tchernovskii (Makarchenko \& Makarchenko 2005, Fig. 26).

\section{Ecology and geographical distribution}

Rheocricotopus costai sp. n. and R. pyrenaeus sp. n. are both rheophilic species exclusively encountered in lotic habitats (peat bogs, springs, upper streams) with siliceous water and low water conductivity. Localities where larvae and pharate adults were collected consist of moderately to weakly shaded ruisselets and cold mountain streams. Bryocolous and hygropetric habitats including waterfalls probably represent the most common aquatic areas for larval populations. Environmental data of habitat recorded along the crenal and upper rhithral of the Rivers Asco (Corsica) and Mantet (Pyrenees) are: siliceous water, low value of conductivity (20-40) $\mu \mathrm{S} / \mathrm{cm}$; pH 5.55.7; temperature $6-12^{\circ} \mathrm{C}$. Such pristine habitats, which are endangered by pastoralism and both natural and accidental flooding, deserve much greater consideration, protection and preservation. Material was collected in some glacial helocrenes and streams delimited by well preserved and protected areas covered by local Nature Reserves located in both Corsica and the Eastern Pyrenees.

The two new species are regarded as typical relict representatives of glacial helocrenes and cold stenothermic streams. They belong to the crenobiontic and crenophilous community of species as documented by Lindegaard (1995). The discovery of $R$. costai $\mathrm{sp} . \mathrm{n}$. and $R$. pyrenaeus sp. n. in such preserved lotic habitats highlights the importance of glacial springs and streams, which are considered to be microrefugia and hotspots of diversity.

Rheocricotopus costai sp. n. is known from both western Corsica and the Eastern Pyrenees, while the geographical distribution of $R$. pyrenaeus $\mathrm{sp}$. n. is currently restricted to springs and streams located in the Eastern Pyrenees. In particular, R. costai sp. n. can be expected to occur in other similar areas all around both the continental and insular Tyrrhenian Provinces (Italy, Spain). This indicates and reinforces the importance of headwaters and cold enclaves in the preservation and persistence of autochthonous glacial relict species, which can be considered as biological indicators of the global warming and climate change in the Mediterranean biogeographical region.

- Associated species encountered in the same localities with $R$. costai sp. n. include: Boreoheptagyia cinctipes (Edwards, 1928); B. dasyops Serra-Tosio, 1989; B. legeri (Goetghebuer, 1933); Diamesa aberrata Lundbeck, 1898; D. cinerella Meigen, 1835; D. macronyx (Kieffer, 1918); D. veletensis Serra-Tosio, 1971; Pseudodiamesa branickii (Nowicki, 1873); Syndiamesa nigra Rossaro, 1980; Bryophaenocladius subvernalis (Edwards, 1929); Chaetocladius laminatus Brundin, 1947; C. suecicus (Kieffer, 1916); Corynoneura tyrrhena Moubayed-Breil, 2015; Eukiefferiella fittkaui Lehmann, 1972; Heleniella ornaticollis (Edwards, 1929); Krenosmittia boreoalpina (Goetghebuer, 1944); Parametriocnemus boreoalpinus Gowin \& Thienemann, 1942; Paratrissocladius orsinii Moubayed-Breil \& Ashe, 2016; Thienemannia corsicana Moubayed-Breil, 2013; T. gracilis Kieffer, 1909.

- Associated species encountered in the same localities with $R$. pyrenaeus sp. n. include: Boreoheptagyia cinctipes (Edwards, 1928); B. legeri (Goetghebuer, 1933); Diamesa aberrata Lundbeck, 1898; D. bertrami Edwards, 1935; D. bohemani Goetghebuer, 1932; D. cinerella Meigen, 1835; D. modesta Serra-Tosio, 1968; D. thomasi Serra-Tosio, 
1970; D. veletensis Serra-Tosio, 1971; Pseudodiamesa branickii (Nowicki, 1873); P. nivosa (Goetghebuer, 1928); Syndiamesa edwardsi Pagast, 1947; S. hygropetrica (Kieffer, 1909); Bryophaenocladius subvernalis (Edwards, 1929); Chaetocladius guisseti Moubayed-Breil, 2017; C. laminatus Brundin, 1947; C. suecicus (Kieffer, 1916); Eukiefferiella fittkaui Lehmann, 1972; Heleniella

\section{References}

1. Albu, P. 1968. Chironomide din Carpaţii româneşti (III). Studii şi Cercetări de Biologie, Série de Zoologie 20: 455-465.

2. Ashe, P. \& O'Connor, J.P. 2012. A World Catalogue of Chironomidae (Diptera). Part 2. Orthocladiinae. Irish Biogeographical Society \& National Museum of Ireland, Dublin. 968 pp.

3. Bhattacharyay, S., Ali, A. \& Chaudhuri, P.K. 1991. Orthoclads of tribe Orthocladiini (Diptera: Chironomidae) from India. Beiträge zur Entomologie, 41(2): 333-349.

4. Brundin, L. 1956. Zur Systematik der Orthocladiinae (Dipt., Chironomidae). Report of the Institute of Freshwater Research, Drottningholm, 37: 5-185.

5. Caspers, N. \& Reiss, F. 1989. Die Chironomidae (Diptera, Nematocera) der Türkei. Teil I: Podonominae, Diamesinae, Prodiamesinae, Orthocladiinae. Entomofauna, 10(8): 105160.

6. Chaudhuri, P.K. \& Sinharay, D.C. 1983. A study on Orthocladiinae (Diptera, Chironomidae) of India. The genus Rheocricotopus Thienemann \& Harnisch. Entomologica Basiliensia, 8: 398-407.

7. Coffman, W.P., Cranston, P.S., Oliver, D.R. \& Sæther, O.A. 1986. The pupae of Orthocladiinae (Diptera, Chironomidae) of the Holarctic Region - Keys and diagnoses. In Wiederholm, T. (ed.): Chironomidae of the Holarctic Region. Keys and diagnoses. Part 2. Pupae. Entomologica Scandinavica, Supplement 28: 147-296.

8. Langton, P.H. 1991. A key to pupal exuviae of the West Palaearctic Chironomidae. Privately published. Huntingdon, England, 386 pp.

9. Langton, P.H. \& Pinder, L.C.V. 2007. Keys to the adult males of Chironomidae of Britain and Ireland. Volume 1 (Pp: 1-239) and volume 2 (Pp: 1-168). Freshwater Biological Association, Scientific Publication, no: 64.

10. Lehmann, J. 1969. Die europäischen Arten der Gattung Rheocricotopus Thien. und Harn. und drei neue Artvertreter dieser Gattung aus der Orientalis (Diptera, Chironomidae). Archiv für Hydrobiologie, 66(3): 348-381.

11. Lindegaard, C. 1995. Chironomidae (Diptera) of European cold springs and factors influencing their distribution. Journal of the Kansas Entomological Society, Supplement 68(2): 108-131.

12. Liu, W., Lin, X. \& Wang, X. 2014a. A review of Rheocricotopus (Psilocricotopus) chalybeatus species group from China, with the description of three new species (Diptera, Chironomidae). ZooKeys, 388: 17-34.

13. Liu, W., Song, C. \& Wang, X. 2014b. Review of the subgenus Rheocricotopus (s. str.) Brundin, 1956 from China (Diptera: Chironomidae). Pan-Pacific Entomologist, 90(2): 100-106. ornaticollis (Edwards, 1929); Krenosmittia boreoalpina (Goetghebuer, 1944); Parametriocnemus boreoalpinus Gowin \& Thienemann, 1942; Rheocricotopus effusus (Walker, 1856); Rheosmittia spinicornis (Brundin, 1956); Thienemannia gracilis Kieffer, 1909 and T. valespira Moubayed-Breil \& Ashe, 2013.

14. Makarchenko, E. \& Makarchenko, M.A. 2005. Chironomids of the genus Rheocricotopus Thienemann and Harnisch, 1932 (Diptera, Chironomidae, Orthocladiinae) of the Russian Far East. Eurasian Entomological Journal, 4(2): 125-136. [In Russian, English Summary]

15. Moubayed-Breil, J. 2016. Rheocricotopus (Psilocricotopus) meridionalis sp. n. and R. (Psc.) thomasi sp. n., two crenophilous species inhabiting cold helocrenes and streams in the Mediterranean Region [Diptera, Chironomidae, Orthocladiinae]. Ephemera, 9(1): 17-32.

16. Moubayed-Breil, J. \& Ashe, P. 2012. An updated checklist of the Chironomidae of Corsica with an outline of their altitudinal and geographical distribution (Diptera). Ephemera, 13(1): 13-39.

17. Moubayed-Breil, J. \& Ashe, P. 2016. New records and additions to the database on the geographical distribution of some threatened chironomid species from continental France (Diptera, Chironomidae). Ephemera, 16(2): 93-108.

18. Ree, H.I. 2013. Description of twelve new species and eight new Korean records of Chironomidae (Diptera) in Korea. Entomological Research Bulletin, 29(2): 142-171.

19. Sasa, M. 1981. Studies on chironomid midges of the Tama River. Part 4. Chironomidae recorded at a winter survey. Research report from the National Institute for Environmental studies, 29: 79-148.

20. Sæther, O.A. 1980. Glossary of chironomid morphology terminology (Diptera, Chironomidae). Entomologica Scandinavica, Supplement, 14: 1-51.

21. Sæther, O.A. 1986. A review of the genus Rheocricotopus Thienemann \& Harnish, 1932, with a description of three new species (Diptera, Chironomidae). Spixiana Supplement, 11: 59-108.

22. Sæther, O.A. \& Schnell, O.A. 1988. Two new species of the Rheocricotopus (R.) effusus-group group (Diptera: Chironomidae). Spixiana, 14: 65-74.

23. Sæther, O.A. \& Spies, M. 2013. Fauna Europaea: Chironomidae. In P. Beuk, P. \& Pape, T. (eds): Fauna Europaea: Diptera Nematocera. Fauna Europaea version 2.6. Internet data base at http://www.faunaeur.org [accessed November 2018].

24. Wang, X. 1995. Rheocricotopus (R.) orientalis, a new species from China (Diptera, Chironomidae). Aquatic Insects, 17(1): 37-40.

25. Wang, X. \& Sæther, O.A. 2001. Two new species of the orientalis group of Rheocricotopus (Psilocricotopus) from China (Diptera, Chironomidae). Hydrobiologia, 444: 237-240.

26. Wang, X. \& Zheng, L. 1989. Two new species of the genus Rheocricotopus from China (Diptera, Chironomidae). Entomotaxonomia, 11(4): 311-313. [In Chinese, English Summary] 